\section{THU0212 REINVESTMENT OF BIOSIMILAR SAVINGS: WHAT ARE THE BEST OPTIONS?}

\section{Martin, R. Campbell, J. Jacob. Consulting, Syneos Health, London, UK}

Background: Biosimilars are becoming available for many of the biologic compounds in rheumatoid arthritis (RA). Biosimilars provide similar benefit at a reduced cost, therefore generating potential savings to the health care system. Objectives: To investigate whether it is most beneficial to reinvest biosimilar savings to treat additional RA patients or whether this same budget would be more beneficially spent on alternative treatments from a UK payer perspective.

Methods: We developed a model to first estimate the savings obtained from using biosimilars from a UK National Health Service (NHS) perspective. Then we identified five treatment alternatives, in addition to RA: melanoma, hepatitis $\mathrm{C}$ (HepC), multiple sclerosis (MS), Duchenne's disease (MD), and non-small cell lung cancer (NSCLC). These indications were considered because of their burden of illness, high cost but high efficacy treatments being available which are associated with investment pressures. The treatments selected were: ataluren (MD), natalizumab (MS), pembrolizumab (melanoma), crizotinib (NSCLC), sofosbuvir + ribavirin (HepC), and etanercept biosimilar. We estimated the health gain (expressed as QALYs) that could be obtained from treating the patients in the four indications of interest using the available savings to identify the most costeffective way to spend the savings. Data on QALY gains were obtained from published sources, mostly HTA assessments.

Results: Based on a biologics expenditure of $\sim £ 430$ million, we estimated that $\sim 55$ million in savings would be generated over a 5 year period.

Based on the outcome of QALY maximisation, over a 5 year period, biosimilar savings in the UK are best spent on treatments in hepatitis C, followed by NSCLC and melanoma. Re-investment in an RA biosimilar only came in 5th place, before cystic fibrosis.

Conclusions: In a country like the UK, where patients have ready access to biologicals, the savings from prescribing biosimilars can be better spent, if QALY maximisation is desired, on non-RA therapies where over a 5 year period more QALYs are generated. On the basis of the research, payers should consider the potential to reinvest biosimilar savings in disease areas with higher QALY yields. Disclosure of Interest: None declared

DOI: 10.1136/annrheumdis-2018-eular.6503

\section{THU0213 \\ ADHERENCE AND PERSISTENCE TO DISEASE MODIFYING ANTI RHEUMATIC DRUGS IN COLOMBIAN PATIENTS WITH RHEUMATOID ARTHRITIS}

N. Pertuz-Charris ${ }^{1}$, F.L. Ochoa-Jaramillo ${ }^{2}$, D. Gil-Calderón ${ }^{1}$, M.A. Alzate-Vinasco ${ }^{1}$, V. Vélez-Marín ${ }^{1}$, D. Hernández-Parra ${ }^{3}$, R. Pineda-Tamayo ${ }^{1} .{ }^{1}$ Rheumatology, Artmedica IPS: ${ }^{2}$ Public health group, CES University, ${ }^{3}$ Clinical research department, Artmedica IPS, Medellín, Colombia

Background: Adherence in the treatment of rheumatoid arthritis (RA) ranges $20 \%$ to $70 \%$ in worldwide population. ${ }^{1}$ In Colombia there are no studies comparing adherence and persistence to conventional and biological treatment.

Objectives: To determine adherence and persistence and associated factors to the treatment of conventional disease-modifying anti-rheumatic drugs (cDMARD) and biological DMARD (bDMARD) in patients with RA under real world data.

Methods: We conducted an observational, analytical retrospective cohort study from January 2015 to December 2016. The study population was 552 RA patients older than 18 years who received any CDMARD treatment in monotherapy or combined with two or more cDMARD and bDMARD (Rituximab and Tofacitinib were excluded). Clinical information was obtained from electronic clinical records and Morisky-Green test was performed during the follow-up. Univariate analysis (proportions and medians), bivariate analysis [relative risk (RR)] and multivariate analysis (logistic regression and Kaplan-Meier survival curve) were developed. Results: Eighty nine percent were women, the median age was 59 years, $50 \%$ have $\geq 12$ years of duration of disease. Adherence for cDMARD was $61 \%$ and for bDMARD $56 \%$. There was an association between adherence and high degree education level (adjusted RR=2.1; $\mathrm{Cl}: \mathbf{1 . 0 9 - 4 . 1 4 )}$ ) and non-adherence with clinical factors such as high disease activity (adjusted RR $=0.41 ; \mathrm{Cl}: \mathbf{0 . 2 2}-0.75$ ); in the CDMARD group the greatest persistence was leflunomide (mean: 631 days) followed by methotrexate (mean: 526 days) and in the bDMARD group was etanercept (mean 1577 days) and tocilizumab (mean 1064 days). Patients with social support had greater persistence in the treatment with cDMARD (adjusted HR=2.1; Cl: 1.11-4.28)

Abstract THU0213 - Table 1. Sociodemographic, clinical and therapeutic characteristics in 552 Colombian patients with rheumatoid arthritis

\begin{tabular}{lccc}
\hline Characteristics & & $\mathbf{n}$ & (\%) \\
\hline $\begin{array}{l}\text { Rheumatoid } \\
\text { factor }\end{array}$ & $(+)$ & 415 & 81 \\
\hline ACPA & $(+)$ & 150 & 71
\end{tabular}

\begin{tabular}{cccc} 
DAS-28 & \multicolumn{1}{c}{$<2,6$} & 267 & 49 \\
& $2,6-3,2$ & 68 & 12 \\
$3,2-4,9$ & 129 & 23 \\
& $>5$ & 88 & 16 \\
cDMARD & Methotrexate & 281 & 55 \\
& Leflunomide & 130 & 25 \\
bDMARD & Sulfasalazine & 71 & 14 \\
& Chloroquine & 30 & 6 \\
& Tocilizumab & 41 & 24 \\
& Adalimumab & 38 & 22 \\
& Abatacept & 32 & 19 \\
& Etanercept & 29 & 17 \\
Infliximab & 14 & 8,2 \\
Golimumab & 11 & 6,4 \\
Certolizumab & 6 & 3,5 \\
\hline
\end{tabular}

IQR: interquartile range, ACPA: anti-cyclic citrullinated protein/peptide antibodies

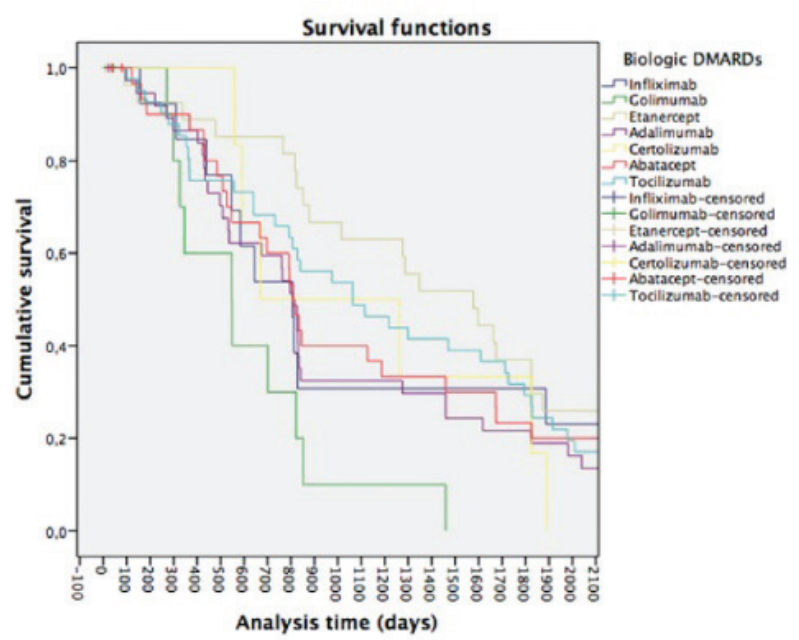

Abstract THU0213 - Figure 1. The median time of follow-up of the studied population was 822 days, IQR 429-727 days.

Conclusions: In real world data, education level and disease activity significantly impact adherence level in RA patients. Social support positively impacts the persistence of the treatment of RA patients, which suggest the implementation of care programs taking this aspect into consideration in order to improve outcomes.

\section{REFERENCE:}

[1] De Klerk E, van der Heijde D, Landewé R, van der Tempel H, Urquhart J, van der Linden S. Patient compliance in rheumatoid arthritis, polymyalgia rheumatica, and gout. J Rheumatol 2003;(1):44-54.

Disclosure of Interest: None declared

DOI: 10.1136/annrheumdis-2018-eular.6091

\section{THU0214 PREDICTIVE FACTORS FOR ACHIEVEMENT OF LOW DISEASE ACTIVITY AT 52 WEEKS ARE DIFFERENT BETWEEN YOUNG AND ELDERLY RHEUMATOID ARTHRITIS PATIENTS TREATED WITH ABATACEPT}

N. Takahashi, T. Kojima, S. Asai, N. Ishiguro, on behalf of the TBCR study group Orthopaedic Surgery, Nagoya University Graduate School Of Medicine, Nagoya, Japan

Background: Japanese post-marketing survey (PMS) data demonstrated that the clinical efficacy of abatacept was similar between the young and elderly rheumatoid arthritis (RA) patients, while they have quite different characteristics including age, disease duration, and concomitant drugs. We hypothesised that the predictive factors for clinical outcomes of abatacept were different between the young and elderly patients.

Objectives: We studied the predictive factors for good clinical response of abatacept in the young and elderly patients, respectively, in this study.

Methods: Participants were consecutive 463 RA patients treated with abatacept and observed for longer than 52 weeks in the TBCR, a Japanese multicenter registry system for RA patients treated with biologics. Univariate and multivariate logistic regression analysis was used to study predictive factors for achievement 